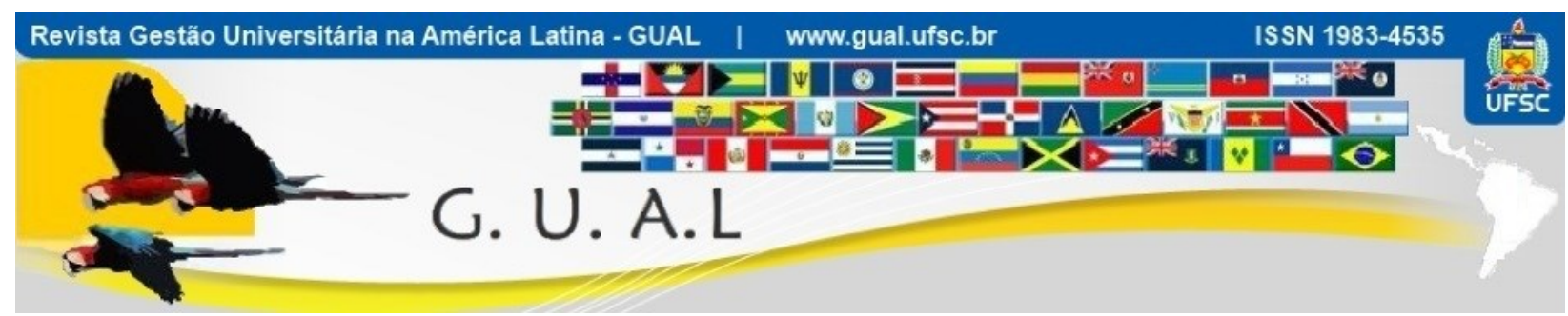

DOI: http://dx.doi.org/10.5007/1983-4535.2019v12n1p73

\title{
A ESTRUTURA ORGANIZACIONAL DA UNIVERSIDADE FEDERAL DO CEARÁ (UFC): UM ESTUDO DE CASO À LUZ DA TEORIA DAS CINCO CONFIGURAÇÕES DE MINTZBERG
}

\author{
THE ORGANIZATIONAL STRUCTURE OF CEARÁ FEDERAL UNIVERSITY \\ (UFC): A CASE BASED ON MINTZBERG'S STRUCTURE OF FIVE THEORY
}

Tainah Pinheiro Moreira, Mestre

https://orcid.org/0000-0001-7048-7836 tainahpm@gmail.com

Universidade Federal do Ceará | Programa de Pós-Graduação em Administração e Controladoria Fortaleza | Ceará | Brasil

Davi Sampaio Marques, Mestre https://orcid.org/0000-0001-5946-0317 davisampaio@oi.com.br

Universidade Federal do Ceará | Programa de Pós-Graduação em Administração e Controladoria Fortaleza | Ceará | Brasil

Sandra Maria dos Santos, Doutora https://orcid.org/0000-0002-8515-9146 smsantos@ufc.br Universidade Federal do Ceará | Programa de Pós-Graduação em Administração e Controladoria Fortaleza $\mid$ Ceará | Brasil

Augusto Cézar de Aquino Cabral, Doutor https://orcid.org/0000-0001-8248-4886

cabral@ufc.br

Universidade Federal do Ceará | Programa de Pós-Graduação em Administração e Controladoria Fortaleza $\mid$ Ceará | Brasil

Maria Naiula Monteiro Pessoa, Doutora https://orcid.org/0000-0002-1233-3596 naiula@ufc.br

Universidade Federal do Ceará | Programa de Pós-Graduação em Administração e Controladoria Fortaleza $\mid$ Ceará $\mid$ Brasil

Recebido em 18/agosto/2016

Aprovado em 23/abril/2018

Publicado em 02/janeiro/2019

Sistema de Avaliação: Double Blind Review

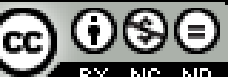

Esta obra está sob uma Licença Creative Commons Atribuição-Uso. 


\title{
RESUMO
}

Com a abordagem gerencial na administração pública a partir da década de 1990, a gestão das instituições de ensino veio perdendo o cunho puramente pedagógico e assumindo um papel mais gerencial, o que demanda uma maior discussão acerca dos modelos de gestão existentes nas Instituições Federais de Ensino Superior (IFES). A teoria das cinco configurações de Mintzberg (2008), lente teórica deste trabalho, propõe cinco tipologias básicas nas quais as estruturas organizacionais podem ser classificadas. Portanto, o objetivo geral desse artigo foi analisar de que modo a configuração organizacional predominante da Universidade Federal do Ceará (UFC) contribui na consecução de seus objetivos institucionais. Os seguintes objetivos específicos foram propostos: identificar o principal mecanismo de coordenação da UFC; identificar a parte-chave da estrutura organizacional da UFC; identificar o tipo de descentralização prevalecente na UFC; identificar as dificuldades ocasionadas pela configuração organizacional da UFC e identificar os facilitadores proporcionados pela configuração organizacional da UFC. Dessa forma, foram realizados uma pesquisa bibliográfica e documental e um estudo de caso, cuja unidade de análise foi a estrutura organizacional da UFC. Concluiu-se que a configuração organizacional predominante da UFC é um híbrido entre burocracia mecanizada e burocracia profissional. Quanto aos objetivos institucionais, observou-se que a configuração organizacional atual proporciona mais dificuldades do que facilidades para a sua consecução.

Palavras-chave: Gestão Universitária. Estrutura Organizacional. Mintzberg. UFC.

\begin{abstract}
With the management approach in the public governance since the 1900 decade, the administration of educational institutions has been losing its purely educational nature and taking a stronger management role, which requires a larger discussion about the existing management models in the federal government universities. Mintzberg's structure of five theory (2008), theoretical lens of this work, proposes five basics typologies in which organizational structures can be classified. Therefore, the main objective of this paper was to analyze how the predominant type of organizational structure from Ceará Federal University (UFC) contributes to the achievement of its institutional objectives. The following specific objectives were proposed: identify the main coordination mechanism from UFC; identify the key part of UFC's organizational structure; identify the type of decentralization prevailing in UFC; identify the difficulties caused by UFC's organizational setup and identify the facilitators provided by UFC's organizational setup. In this way, were realized a bibliographic and documentary research and a case study, which unit of analysis was UFC's organizational structure. It was concluded that UFC's predominant type of organizational structure is a hybrid between mechanized bureaucracy and professional bureaucracy. About the institutional objectives, it was observed that the current organization setup provides more difficulties than facilities for its achievement.
\end{abstract}

Keywords: University Management. Organizational Structure. Mintzberg. UFC. 


\section{INTRODUÇÃO}

O estudo da estrutura organizacional vem sendo discutido há bastante tempo: a organização da guerra na obra de Sun Tzu; os processos de organização e hierarquias na construção das pirâmides do Egito e, até, o modelo de doze discípulos adotado por Jesus. No âmbito científico, e estrutura organizacional tem sido abordada desde o início do século XX, com a Teoria Clássica da Administração. (TRIGUEIRO FERNANDEZ, 2014). Contudo, apesar de ser um tema bastante antigo, Trigueiro-Fernandez (2014) afirma que não se trata de um assunto que esteja nas grandes vitrines e eventos científicos de administração e reforça que há grande lacunas, o que corrobora com a necessidade de se estudar continuamente as estruturas organizacionais para melhor compreender como elas funcionam e como atingem a eficácia e eficiência nos seus processos nos seus respectivos campos de atuação.

Com a abordagem gerencial na administração pública a partir da década de 1990, a gestão das IFES veio perdendo o cunho puramente pedagógico, assumindo um papel mais gerencial. Isso provocou uma necessidade de renovação conceitual na gestão dessas instituições, proporcionando uma maior participação e ampla compreensão dos atores envolvidos na percepção e discussão do modelo existente. (SOUZA; PRADO, 2009). Essa orientação cada vez mais voltada para a qualidade dos serviços (educacionais) ofertados demanda um conhecimento maior sobre como o trabalho está organizado e as práticas de gestão adotadas pelas diversas IFES. Há, portanto, a necessidade crescente de uma discussão mais abrangente sobre as transformações na estrutura gerencial necessárias para a sustentação das IES. Em muitos casos, estruturas administrativas arcaicas ainda convivem lado a lado com as últimas inovações tecnológicas, nos diversos campos do saber. (PEIXOTO; SOUZA, 2015).

Fachin (2013) observa que alguns modelos gerados na área da gestão privada e pública vêm sendo utilizados para estudar as universidades. O conceito mais conhecido e clássico é o de burocracia, discutido nos estudos de Max Weber, mas modificado para introduzir a ideia da universidade como uma organização em que se confundem características burocráticas e profissionais. Assim, o modelo que se aproxima dessa discussão é o da teoria das configurações de Mintzberg (2008), que é a principal lente teórica do trabalho em questão. A sua proposta consiste em identificar configurações adequadas de estruturas organizacionais, buscando despertar nos gestores e nos estudiosos um anseio por organizações mais eficazes. 


\section{A ESTRUTURA ORGANIZACIONAL DA UNIVERSIDADE FEDERAL DO CEARÁ (UFC): UM ESTUDO DE CASO À LUZ DA TEORIA DAS CINCO CONFIGURAÇÕES DE MINTZBERG \\ DOI: http://dx.doi.org/10.5007/1983-4535.2019v12n1p73}

Diante do exposto, esse artigo buscou responder a seguinte questão de pesquisa: de que modo a configuração organizacional predominante da UFC contribui para atingir seus objetivos institucionais? O objetivo do artigo é analisar, à luz da teoria das configurações de Mintzberg, de que modo a configuração organizacional predominante da UFC contribui para a consecução de seus objetivos institucionais. Os objetivos específicos são: a) identificar o

principal mecanismo de coordenação da UFC; b) identificar a parte-chave da estrutura organizacional da UFC; c) identificar o tipo de descentralização prevalecente na UFC; d) identificar as dificuldades ocasionadas pela configuração organizacional da UFC; e) identificar os facilitadores proporcionados pela configuração organizacional da UFC.

Além dessa introdução, o artigo está estruturado nas seguintes seções: referencial teórico, que aborda a teoria das cinco configurações de Mintzberg (2008) e estudos anteriores sobre configuração organizacional em universidades; metodologia adotada na pesquisa; análise e discussão dos resultados obtidos; considerações finais e as referências utilizadas.

\section{REFERENCIAL TEÓRICO}

Essa sessão tem como objetivo apresentar o referencial teórico utilizado para a realização da pesquisa, sendo dividida entre a Teoria das Configurações Organizacionais de Mintzberg e estudos anteriores que corroboram para a realização desse trabalho.

\subsection{AS CONFIGURAÇÕES ORGANIZACIONAIS DE MINTZBERG}

Para Mintzberg (2008), toda atividade humana organizada demanda duas exigências fundamentais e opostas: a divisão do trabalho em tarefas e a coordenação dessas tarefas para a realização da atividade. Assim, "a estrutura de uma organização pode ser definida simplesmente como a soma total das maneiras pelas quais o trabalho é dividido em tarefas distintas e, depois, como a coordenação é realizada entre essas tarefas.” (MINTZBERG, 2008, p. 12). Além disso, "os elementos da estrutura devem ser selecionados para a obtenção de uma consistência ou harmonia interna, bem como uma consistência básica com a situação da organização.” (MINTZBERG, 2008, p. 13). Dessa forma, a eficácia organizacional está relacionada à maneira como as organizações se estruturam para atender suas demandas internas ou externas. Portanto, dependendo de como as várias escolhas acerca dos componentes estruturais são realizadas, diferentes configurações podem ser desenhadas. Entretanto, para Mintzberg (2008, p. 13): 


\section{A ESTRUTURA ORGANIZACIONAL DA UNIVERSIDADE FEDERAL DO CEARÁ (UFC): UM ESTUDO DE CASO À LUZ DA TEORIA DAS CINCO CONFIGURAÇÕES DE MINTZBERG DOI: http://dx.doi.org/10.5007/1983-4535.2019v12n1p73}

Um número limitado dessas configurações explica a maioria das tendências que levam as organizações eficazes a estruturar-se por si mesmas. Em outras palavras, o design de uma estrutura organizacional eficaz - de fato, mesmo o diagnóstico dos problemas de muitas organizações ineficazes - parece envolver a consideração de apenas algumas configurações básicas.

Sustentado essas afirmações, o autor propõe um conjunto de cinco configurações nas quais qualquer organização pode ser classificada: estrutura simples, burocracia mecanizada, burocracia profissional, forma divisionalizada e adhocracia. Identificar essa classificação, por sua vez, pressupõe analisar três características básicas da configuração: principal mecanismo de coordenação, parte-chave da organização e tipo de descentralização. Conforme o Quadro 1:

Quadro 1 As cinco configurações estruturais

\begin{tabular}{|c|c|c|c|}
\hline $\begin{array}{c}\text { Configuração } \\
\text { estrutural }\end{array}$ & $\begin{array}{c}\text { Principal mecanismo de } \\
\text { coordenação }\end{array}$ & $\begin{array}{c}\text { Parte-chave da } \\
\text { organização }\end{array}$ & Tipo de descentralização \\
\hline Estrutura Simples & Supervisão direta & Cúpula estratégica & Centralização vertical e horizontal \\
\hline $\begin{array}{c}\text { Burocracia } \\
\text { Mecanizada }\end{array}$ & $\begin{array}{c}\text { Padronização dos } \\
\text { processos }\end{array}$ & Tecnoestrutura & $\begin{array}{c}\text { Descentralização horizontal } \\
\text { limitada }\end{array}$ \\
\hline $\begin{array}{c}\text { Burocracia } \\
\text { Profissional }\end{array}$ & $\begin{array}{c}\text { Padronização das } \\
\text { habilidades }\end{array}$ & Núcleo Operacional & $\begin{array}{c}\text { Descentralização vertical e } \\
\text { horizontal }\end{array}$ \\
\hline Forma Divisionalizada & Padronização dos outputs & Linha intermediária & Descentralização vertical limitada \\
\hline Adhocracia & Ajustamento mútuo & Assessoria de apoio & Descentralização seletiva \\
\hline
\end{tabular}

Fonte: Mintzberg (2008, p. 174).

\subsubsection{Mecanismos de coordenação}

Os mecanismos de coordenação são utilizados para explicar as maneiras por meio das quais as organizações coordenam seu trabalho. De acordo com Mintzberg (2008, p. 14), eles “devem ser considerados os elementos mais básicos da estrutura, a 'cola' que mantém as organizações unidas.”. O primeiro mecanismo, encontrado principalmente na adhocracia, é o ajustamento mútuo, no qual a coordenação é obtida por meio de comunicação informal. A supervisão direta, própria da estrutura simples, ocorre quando uma pessoa é responsável pelo trabalho de outras, instruindo e monitorando suas ações. A padronização dos processos, característica da burocracia mecanizada, consiste na especificação ou programação do conteúdo do trabalho; a padronização dos outputs, encontrada na forma divisionalizada, acontece quando os resultados do trabalho são especificadas, como as dimensões de um produto ou uma medida de desempenho; por fim, a padronização das habilidades, identificada 


\section{A ESTRUTURA ORGANIZACIONAL DA UNIVERSIDADE FEDERAL DO CEARÁ (UFC): UM ESTUDO DE CASO À LUZ DA TEORIA DAS CINCO CONFIGURAÇÕES DE MINTZBERG \\ DOI: http://dx.doi.org/10.5007/1983-4535.2019v12n1p73}

na burocracia profissional, trata-se da padronização do próprio trabalhador, ou seja, quando suas habilidades são padronizados por meio um treinamento específico exigido para a execução do trabalho.

\subsubsection{Partes-chave da organização}

As cinco partes básicas descritas por Mintzberg compõem o diagrama completo que corresponde a estrutura organizacional em todas as cinco configurações, conforme a Figura 1; são nessas partes que estão lotadas as pessoas e posicionados seus cargos. Em cada configuração, uma parte se destaca por ser aquela de onde emanam as principais decisões tomadas, essa parte, então, passa a ser identifica como a parte-chave da organização. Na base da organização, o núcleo operacional, encontram-se as pessoas que executam o trabalho, os operários. À medida que a organização cresce, aumenta a necessidade de supervisão direta, obrigando a presença de um gerente no topo da organização, a cúpula estratégica. Quando a organização se torna mais elaborada, são necessários mais gerentes e uma parte chamada linha intermediária é criada entre o núcleo operacional e a cúpula estratégica. À medida que esse processo de elaboração continua, a organização pode aumentar a padronização dos processos de trabalho para melhor coordená-los, nesse caso, a responsabilidade por essa padronização é transferida aos analistas, localizados na tecnoestrutura. Finalmente, a organização pode criar unidades de assessoria para fornecer serviços indiretos, constituindo a assessoria de apoio.

Figura 1 As cinco partes da configuração

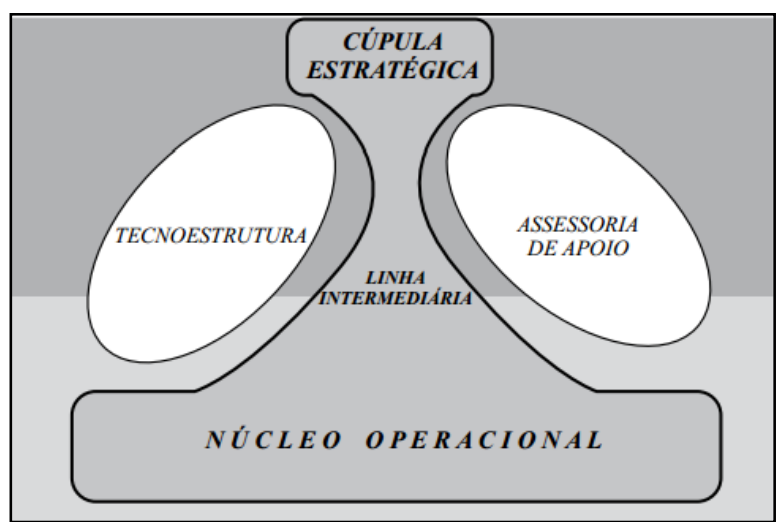

Fonte: Mintzberg (2008, p. 22). 


\subsubsection{Parâmetros de design}

De acordo com Mintzberg (2008, p.36), "no caso da estrutura organizacional, design significa girar os botões que influenciam a divisão do trabalho e os mecanismos de coordenação, que afetam as funções da organização.”. Em sua teoria, portanto, o autor sugere que o design é determinado por meio de nove parâmetros, cada um deles é apresentado a seguir:

- Especialização de tarefa - O trabalho pode ser especializado em duas dimensões: horizontal e vertical. A primeira dimensão diz respeito a quantidade de tarefas em que é dividido um trabalho, de modo que quanto mais especializado é um trabalho mais estreita e repetitiva é a tarefa executada. A segunda dimensão diz respeito ao controle do trabalhador sobre o trabalho, ou seja, em que medida o trabalhador faz seu trabalho sabendo o porquê e como executá-lo.

- Formalização do comportamento - É o modo pelo qual a organização separa seus membros, ou seja, como padroniza seus processos de trabalho. O comportamento pode ser regulamentado por meio de especificações associadas à descrição das tarefas, ao fluxo de trabalho ou a regras.

- Treinamento e doutrinação - Sobre treinamento, Mintzberg (2008, p.52) afirma que "quando um trabalho envolve um corpo de conhecimento e um conjunto de habilidades complexos e não racionalizados, o trabalhador deve passar muito tempo aprendendo-os.". Enquanto que "doutrinação é o rótulo utilizado para o parâmetro de design pelo qual a organização, formalmente, socializa seus membros em seu próprio benefício.”. (MINTZBERG, 2008, p. 53).

- Agrupamento em unidades - O agrupamento em unidades é o meio pelo qual o sistema de autoridade formal é estabelecido e a hierarquia da organização construída. Em bases gerais, pode ser: por mercado, quando se agrupa por fins (por produto, cliente e/ou local) ou por função, quando se agrupo por meios (por conhecimento, habilidade e/ou processo de trabalho).

- Dimensão da unidade - Diz respeito ao tamanho de cada unidade e à amplitude de controle adotada. A estrutura pode ser mais verticalizada, com pequenas unidades e amplitudes de controle estreitas ou mais plana, com grandes unidades e amplitudes de controle maiores.

- Sistema de planejamento e controle - O plano especifica os padrões desejados e o controle se o padrão foi atingido ou não. Juntos, regulam os outputs e, indiretamente, o comportamento.

- Instrumentos de interligação - Instrumentos desenvolvidos para encorajar contatos de interligação entre indivíduos, sempre que seja necessário manter interdependência entre diferentes unidades. Esses instrumentos formalizam o ajuste mútuo, tipicamente alcançado por meio da comunicação informal, pois são incorporados à estrutura formal da organização.

- Tipo de descentralização - Diz respeito à terceira característica básica sugerida por Mintzberg (2008) na análise das cinco configurações. Essa característica baseia-se 
em dois parâmetros de design essenciais: a descentralização vertical, quando o poder formal se dispersa cadeia abaixo de autoridade da linha; e a descentralização horizontal, que se refere à extensão em que os não-gerentes controlam os processos de decisão. Assim, o autor descreve como se dá, em cada uma das tipologias, o processo de centralização e descentralização do poder sobre as decisões:

- Tipo A - Centralização vertical e horizontal: o executivo principal retém o poder decisório e coordena sua execução por supervisão direta;

- Tipo B - Descentralização horizontal limitada (seletiva): a organização confia na padronização dos processos de trabalho, atribuindo papel de liderança aos analistas;

- Tipo C - Descentralização vertical limitada (paralela): a organização está dividida em unidades de mercado ou divisões, cujos gerentes recebem delegação (paralela) de poder decisório sobre seus mercados;

- Tipo D - Descentralização vertical e horizontal seletivas: o poder é delegado às constelações de trabalho em vários níveis hierárquicos, que utilizam a assessoria conforme a dimensão técnica das decisões;

- Tipo E - Descentralização vertical e horizontal: o poder de decisão está na base, ou seja, encontra-se com não-gerentes, os operadores.

\subsection{ESTUDOS SOBRE CONFIGURAÇÕES ORGANIZACIONAIS NAS UNIVERSIDADES}

Um dos estudos brasileiros pioneiros na temática, a dissertação de Marks (1993), faz uma análise da Universidade de Ijuí à luz da teoria de Mintzberg. Segundo o autor, há uma crescente complexidade nas universidades devido aos aspectos políticos internos e à natureza competitiva do mercado. Ao analisar a Universidade, concluiu que ela se enquadraria no tipo "Burocracia profissional" com forte conotação de "Arena política" e que mudanças no processo administrativo estratégico eram necessárias para atender às demandas do quadro encontrado.

Outra pesquisa, mais abrangente, foi a que resultou na tese de Freitas (2002), um estudo multicasos em três universidades federais brasileiras, dentre elas a UFC. De acordo com a autora, as universidades, na década de 90, estiveram inseridas em contextos complexos e dinâmicos, que exigiram uma nova forma de se adaptar, modificando sua configuração estratégica. Assim, com base na abordagem da configuração e partindo do pressuposto de que é possível observar o comportamento estratégico das universidades no processo de adequação ao contexto ambiental, a autora desenvolveu um novo modelo de análise, baseado nas Teorias da Administração, para o que ela chamou de "configuração estratégica". Adicionalmente, 


\section{A ESTRUTURA ORGANIZACIONAL DA UNIVERSIDADE FEDERAL DO CEARÁ (UFC): UM ESTUDO DE CASO À LUZ DA TEORIA DAS CINCO CONFIGURAÇÕES DE MINTZBERG \\ DOI: http://dx.doi.org/10.5007/1983-4535.2019v12n1p73}

utilizando-se dos estudos de Mintzberg (1979), Freitas (2002) concluiu que a UFC classificase como uma transição entre a "Burocracia mecanizada" e a "Burocracia profissional".

Nesse contexto de transição e mudanças, Vieira e Vieira (2003) criticam o crescimento do aparato-meio, que se contrapõe às atividades-fim e compromete a qualidade dos resultados. Afirmam que as formas tradicionais de gestão do desempenho, concentradas numa hierarquia extremamente verticalizada, nos planos de carreira e na isonomia salarial, acabam dificultando a excelência acadêmica das instituições. Assim, discutem a necessidade um modelo pós-burocrático para as instituições de ensino, com maior flexibilidade e horizontalidade, particularmente na gestão acadêmica, para um melhor desempenho. (VIEIRA; VIEIRA, 2003).

Pelo fato de exercerem serviços de natureza pública, as universidades públicas são regulamentadas e sofrem bastante influência em seus contextos legais e governamentais. Nesse sentido, Losekann e Saldanha (2007) fazem uma relação entre a configuração das universidades públicas brasileiras e as reformas administrativas ocorridas no Brasil, principalmente no âmbito educacional, desde os governos do regime militar até a legislação mais recentes. Para as autoras, mesmo que esteja intimamente ligada aos planos econômicos governamentais, a estrutura organizacional das universidade precisa ser rediscutida por seus dirigentes e demais interessados com base nos anseios de uma universidade pública e democrática. E concluem que o melhor modelo para esse propósito é o da "Burocracia Profissional" de Mintzberg.

Mais recentes, são a tese de Pinheiro (2011) e a dissertação de Trigueiro-Fernandez (2014). O primeiro buscou analisar o redesenho das configurações estruturais da UFC, tendo como enfoque a inovação e a flexibilidade demandadas pós-LDB. $\mathrm{O}$ autor procurou entender como as legislações e as mudanças ocorridas influenciaram no redesenho dessa configuração no período analisado e concluiu que a UFC é uma "Burocracia profissional" com uma tendência de se deslocar para uma "Organização diversificada”. Já Trigueiro-Fernandes (2014) realizou um estudo de caso em que analisa a estrutura organizacional da Universidade Federal do Rio Grande do Norte e sua relação com o desempenho organizacional. Para o pesquisador, existe uma demanda constante por maior modernização da configuração organizacional das universidades, de modo que possam acompanhar o crescimento da sua atuação na sociedade. 


\section{A ESTRUTURA ORGANIZACIONAL DA UNIVERSIDADE FEDERAL DO CEARÁ (UFC): UM ESTUDO DE CASO À LUZ DA TEORIA DAS CINCO CONFIGURAÇÕES DE MINTZBERG DOI: http://dx.doi.org/10.5007/1983-4535.2019v12n1p73}

Assim, os estudos aqui apresentados reforçam a relevância desse trabalho para a problematização da temática da configuração organizacional das universidades brasileiras, com foco no cumprimento dos objetivos institucionais, o que representa uma diferença em relação aos estudos anteriores. A seguir, é apresentado um quadro-resumo desses estudos (Quadro2):

Quadro 2 Síntese dos estudos anteriores

\begin{tabular}{|c|c|c|c|}
\hline Autoria & $\begin{array}{c}\text { Objetivos } \\
\end{array}$ & Metodologia & Resultados \\
\hline $\begin{array}{l}\text { Marks } \\
(1993)\end{array}$ & $\begin{array}{l}\text { Descrever, com base na } \\
\text { teoria de Mintzberg, como } \\
\text { está estruturada, como } \\
\text { funciona e que influências } \\
\text { atuam sobre a Universidade } \\
\text { de Ijuí. }\end{array}$ & $\begin{array}{l}\text { Estudo de } \\
\text { caso único e } \\
\text { pesquisa } \\
\text { documental. }\end{array}$ & $\begin{array}{l}\text { A configuração é do tipo "Burocracia } \\
\text { Profissional", com crescente conotação } \\
\text { de "Arena Política". Propõe mudanças } \\
\text { no processo administrativo estratégico } \\
\text { da UNIJUÍ. }\end{array}$ \\
\hline $\begin{array}{l}\text { Freitas } \\
(2002)\end{array}$ & $\begin{array}{l}\text { Analisar, com base na } \\
\text { abordagem da configuração, } \\
\text { o comportamento } \\
\text { estratégico de universidades } \\
\text { federais no processo de } \\
\text { adequação ao contexto } \\
\text { ambiental. }\end{array}$ & $\begin{array}{l}\text { Estudo } \\
\text { multicasos } \\
\text { envolvendo } 3 \\
\text { universidade } \\
\mathrm{s} \text { federais } \\
\text { brasileiras. }\end{array}$ & $\begin{array}{l}\text { Na década de } 90 \text {, as universidades } \\
\text { estiveram inseridas em um contexto } \\
\text { complexo e dinâmico, adequando-se a } \\
\text { configuração estratégica de adaptação } \\
\text { incremental com base nas concepções } \\
\text { determinista e voluntarista. }\end{array}$ \\
\hline $\begin{array}{l}\text { Vieira e } \\
\text { Vieira } \\
(2003)\end{array}$ & $\begin{array}{l}\text { Discutir a realidade das } \\
\text { IFES, a perspectiva futura } \\
\text { de inovação estrutural e a } \\
\text { implementação de novas } \\
\text { formas de organização. }\end{array}$ & $\begin{array}{c}\text { Pesquisa } \\
\text { bibliográfica. }\end{array}$ & $\begin{array}{l}\text { Sugere uma estrutura organizacional } \\
\text { com maior flexibilidade e } \\
\text { horizontalidade e propõe um sistema } \\
\text { pós-burocrático, simples, } \\
\text { informatizada e racional. }\end{array}$ \\
\hline $\begin{array}{l}\text { Losekann } \\
\text { e } \\
\text { Saldanha } \\
\text { (2007) }\end{array}$ & $\begin{array}{l}\text { Desvelar o atual estado de } \\
\text { mudança das universidades } \\
\text { federais e compreender o } \\
\text { relacionamento entre } \\
\text { estrutura organizacional, } \\
\text { poder e as reformas } \\
\text { políticas. }\end{array}$ & $\begin{array}{c}\text { Pesquisa } \\
\text { bibliográfica. }\end{array}$ & $\begin{array}{l}\text { Os dirigentes e demais interessados } \\
\text { devem propor uma estrutura } \\
\text { organizacional para as universidades } \\
\text { que satisfaça aos anseios de uma } \\
\text { universidade pública e democrática e } \\
\text { não a planos econômicos. }\end{array}$ \\
\hline $\begin{array}{l}\text { Pinheiro } \\
\text { (2011) }\end{array}$ & $\begin{array}{l}\text { Examinar em que medida as } \\
\text { características de inovação } \\
\text { e flexibilidade da legislação } \\
\text { pós-LDB influenciaram o } \\
\text { redesenho da estrutura } \\
\text { organizacional da UFC. }\end{array}$ & $\begin{array}{c}\text { Pesquisa } \\
\text { documental e } \\
\text { de campo. }\end{array}$ & $\begin{array}{l}\text { Devido a dificuldade de incorporar a } \\
\text { nova legislação, a UFC vem copiando } \\
\text { soluções exógenas e utilizando } \\
\text { soluções improvisadas, levando a } \\
\text { superposição de competências por } \\
\text { duplicação de estruturas com } \\
\text { propósitos idênticos. }\end{array}$ \\
\hline $\begin{array}{l}\text { Trigueiro- } \\
\text { Fernandes } \\
\text { (2014) }\end{array}$ & $\begin{array}{l}\text { Analisar quais são os } \\
\text { componentes da estrutura } \\
\text { organizacional da UFRN e } \\
\text { em que medida eles afetam } \\
\text { o desempenho } \\
\text { organizacional. }\end{array}$ & $\begin{array}{l}\text { Pesquisa de } \\
\text { campo, com } \\
\text { uso de } \\
\text { métodos } \\
\text { quantitativos. }\end{array}$ & $\begin{array}{l}\text { Formalização, comunicação, } \\
\text { treinamento descentralização e } \\
\text { internalização afetam positivamente. } \\
\text { Departamentalização afeta } \\
\text { negativamente e hierarquização não } \\
\text { apresentou relação significativa. }\end{array}$ \\
\hline
\end{tabular}

Fonte: Elaborado pelos autores (2016). 


\section{A ESTRUTURA ORGANIZACIONAL DA UNIVERSIDADE FEDERAL DO CEARÁ (UFC): UM ESTUDO DE CASO À LUZ DA TEORIA DAS CINCO CONFIGURAÇÕES DE MINTZBERG \\ DOI: http://dx.doi.org/10.5007/1983-4535.2019v12n1p73}

\section{METODOLOGIA}

Nesta seção, a metodologia para a realização do trabalho é definida quanto à tipologia e estratégia de pesquisa adotadas, aos meios utilizados, aos métodos escolhidos para coleta de dados e, por fim, à forma como a análise dos dados foi realizada.

A tipologia adotada foi do tipo qualitativa descritiva, cujo objetivo é "dizer como é e como se manifesta determinado fenômeno" (SAMPIERI; COLLADO; LUCIO, 2013, p. 100). No que se refere aos meios, foi realizada pesquisa bibliográfica, documental e de campo. A estratégia de pesquisa utilizada foi o estudo de caso, uma "investigação empírica que investiga um fenômeno contemporâneo dentro de seu contexto da vida real, especialmente quando os limites entre o fenômeno e o contexto não estão claramente definidos." (YIN, 2010, p. 32). Para tanto, realizou-se um estudo de caso único, na Universidade Federal do Ceará, cuja unidade de análise trabalhada foi a sua estrutura organizacional.

O método de coleta de dados escolhido foi a entrevista semiestruturada, cujo roteiro foi elaborado a partir da lente teórica principal de pesquisa, a teoria das configurações de Mintzberg, com foco nos cinco objetivos específicos propostos por esse trabalho e de acordo com as categorias de análise definidas no último parágrafo desta seção. Assim, as entrevistas foram aplicadas a servidores da UFC, escolhidos com base no critério de amostragem por julgamento, em função de estarem lotados em partes estratégicas da organização e ocuparem cargos cujo poder de decisão tem grande impacto nas características da configuração organizacional. Dessa forma, foram realizadas quatro entrevistas com os ocupantes dos seguintes cargos: Vice-Reitor, Pró-Reitor de gestão de pessoas, Coordenador de planejamento e gestão estratégica da Pró-Reitoria de Planejamento - PRPL e Diretor da Divisão de Dimensionamento e Movimentação de Pessoal da Pró-Reitoria de Gestão de Pessoas PROGEP. Mediante autorização de todos entrevistas, as quatro sessões foram gravadas e, em seguida, transcritas, como parte da primeira etapa da análise de dados. Devido à solicitação de anonimato de um dos entrevistados, optou-se por manter os nomes de todos em anônimo, sendo identificados por meio dos seguintes códigos: E1, E2, E3 e E4.

A pesquisa documental consistiu na análise do Estatuto da UFC (UFC, 2015a), da Estrutura organizacional (UFC, 2015b) e do Regimento Geral da UFC (UFC, 2015c). De acordo com Martins (2008, p. 46 apud CUNHA; YOKOMIZO; BONACIM, 2010, p. 11), "a realização de pesquisa documental é necessária para corroborar evidências coletadas por outros instrumentos e outras fontes, possibilitando a confiabilidade de achados por meio de 


\section{A ESTRUTURA ORGANIZACIONAL DA UNIVERSIDADE FEDERAL DO CEARÁ (UFC): UM ESTUDO DE CASO À LUZ DA TEORIA DAS CINCO CONFIGURAÇÕES DE MINTZBERG \\ DOI: http://dx.doi.org/10.5007/1983-4535.2019v12n1p73}

triangulação de dados e de resultados.”. Para Cunha; Yokomizo; Bonacim (2010, p. 11), "ao realizar uma entrevista com um gestor: um documento corporativo pode servir de sustentação, complemento ou contraponto ao que foi coletado na entrevista, servindo de evidência para confirmações e análises do pesquisador.”. Além disso, segundo Patton (2002 apud CUNHA; YOKOMIZO; BONACIM, 2010, p. 12), “em uma pesquisa de campo, a análise prévia de documentos relevantes da organização pode servir também de base para guiar perguntas e o próprio roteiro de uma posterior entrevista.", ou seja, "ela serviria de base para preparar um método de coleta de dados principal, deixando-o mais robusto e sustentando em sua posterior aplicação.” (CUNHA; YOKOMIZO; BONACIM, 2010, p. 12).

A análise dos dados coletados foi realizada mediante procedimento analítico geral, em que os dados são transformados em registros escritos e posteriormente codificados (COLLIS; HUSSEY, 2005). Assim, após transcritas as entrevistas e tendo como ponto de partida os objetivos específicos a que se propõe esse trabalho, foram definidas quatro categorias principais de codificação: principal mecanismo de coordenação, parte-chave da estrutura organizacional, tipo de descentralização prevalecente e dificuldades e facilitadores proporcionados pela configuração organizacional da UFC. Essas categorias são tratadas na quarta seção desse trabalho, análise e discussão dos resultados, cada uma em subtópico próprio. Para cada categoria foram definidas subcategorias, de acordo com o referencial teórico utilizado e, em seguida, para cada subcategoria, foram identificadas palavras-chaves e destacados os trechos das entrevistas pertinentes à análise e discussão dos resultados (Quadro $3)$.

\subsection{A UNIVERSIDADE FEDERAL DO CEARÁ}

A UFC é instituição federal de ensino superior, caracterizada como uma autarquia educacional de regime especial, criada pela lei 2.373 de 1954 e vinculada ao Ministério da Educação (MEC). A universidade detém autonomia didático-científica, administrativa e de gestão financeira e patrimonial e busca atender ao princípio da indissociabilidade entre o ensino, a pesquisa e extensão (UFC, 2015a). De acordo o Estatuto, seus objetivos são: “[...] preservar, elaborar, desenvolver e transmitir o Saber em suas várias formas de conhecimento, puro e aplicado." (UFC, 2015a). Sua organização e seu funcionamento são regidos pelos seguintes documentos: Estatuto; Regimento Geral; regimentos específicos de órgãos colegiados superiores e órgãos administrativos; e pelas resoluções aprovadas no Conselho 
Universitário (CONSUNI) e no Conselho de Ensino, Pesquisa e Extensão (CEPE). (UFC, 2015c).

Quadro 3 Relação entre objetivos específicos, categorias de análise e subcategorias

\begin{tabular}{|c|c|c|}
\hline Objetivo específico & Categoria de análise & Subcategorias de análise \\
\hline \multirow{5}{*}{$\begin{array}{l}\text { Identificar o principal mecanismo de } \\
\text { coordenação }\end{array}$} & \multirow{5}{*}{$\begin{array}{l}\text { Principal mecanismo de } \\
\text { coordenação }\end{array}$} & Ajuste mútuo \\
\hline & & Supervisão direta \\
\hline & & Padronização de processos \\
\hline & & Padronização de resultados \\
\hline & & Padronização de habilidades \\
\hline \multirow{5}{*}{$\begin{array}{l}\text { Identificar a parte-chave da estrutura } \\
\text { organizacional }\end{array}$} & \multirow{5}{*}{$\begin{array}{l}\text { Parte-chave da estrutura } \\
\text { organizacional }\end{array}$} & Cúpula estratégica \\
\hline & & Gerência intermediária \\
\hline & & Tecnoestrutura \\
\hline & & Assessoria de apoio \\
\hline & & Núcleo operacional \\
\hline \multirow{7}{*}{$\begin{array}{l}\text { Identificar o tipo de descentralização } \\
\text { prevalecente }\end{array}$} & \multirow{7}{*}{$\begin{array}{l}\text { Tipo de descentralização } \\
\text { prevalecente }\end{array}$} & Especialização horizontal \\
\hline & & Especialização vertical \\
\hline & & Treinamento \\
\hline & & Doutrinação \\
\hline & & Instrumentos de interligação \\
\hline & & Agrupamento de unidades \\
\hline & & Tomada de decisão \\
\hline $\begin{array}{l}\text { Identificar os facilitadores } \\
\text { proporcionados pela configuração } \\
\text { organizacional da UFC }\end{array}$ & \multirow{2}{*}{$\begin{array}{l}\text { Dificuldades e } \\
\text { facilitadores } \\
\text { proporcionados pela } \\
\text { configuração } \\
\text { organizacional da UFC }\end{array}$} & Dificuldades \\
\hline $\begin{array}{l}\text { Identificar as dificuldades } \\
\text { proporcionadas pela configuração } \\
\text { organizacional da UFC }\end{array}$ & & Facilitadores \\
\hline
\end{tabular}

Fonte: Elaborado pelos autores (2016).

Quanto à sua estrutura organizacional, a Universidade apresenta dois organogramas, um referente ao à Administração Superior e outro à Administração Acadêmica. Dentre os órgãos da Administração Superior, estão presentes no topo da estrutura: Reitoria, ViceReitoria CONSUNI, CEPE e o Conselho de Curadores. Logo abaixo, órgãos como Superintendência de Infraestrutura e Ouvidoria Geral. Seguem-se órgãos suplementares como a Biblioteca Universitária, a Secretaria de Tecnologia da Informação (STI), e a Secretaria de Cultura Artística. E na base desse primeiro organograma estão presentes sete pró-reitorias: Pró-Reitoria de Pesquisa e Pós-graduação (PRPPG); Pró-Reitoria de Graduação (PROGRAD); Pró-Reitoria de Extensão (PREX); Pró-Reitoria de Planejamento (PRPL); PróReitoria de Gestão de Pessoas (PROGEP); e Pró-Reitoria de Assuntos Estudantis (PRAE). (UFC, 2015b). Na estrutura da Administração Acadêmica, estão presentes no topo: os conselhos (de centros, departamentais, dos campi e dos institutos). E logo abaixo estão 
localizados os campi do interior, faculdades, institutos e centros com seus respectivos cursos e departamentos de ensino. (UFC, 2015b).

\section{ANÁLISE E DISCUSSÃO DOS RESULTADOS}

A partir dos dados coletados por meio das entrevistas, de acordo com os procedimentos analíticos explicitados na metodologia, assim como, a partir das pesquisas documental e bibliográfica realizadas, no que concerne ao referencial teórico exposto, segue-se a análise e discussão dos resultados no sentido de responder a pergunta de pesquisa através da discussão de cada um dos seus objetivos específicos. Esta seção é organizada com base nas quatro principais categorias de análise identificadas.

\subsection{PRINCIPAL MECANISMO DE COORDENAÇÃO}

Dos cinco mecanismos de coordenação trabalhados por Mintzberg em sua teoria, a padronização dos processos de trabalho foi o mecanismo mais apontado pelos entrevistados como predominante na forma como a UFC coordena o seu trabalho, seguido pela padronização das habilidades e, depois, pela padronização dos resultados. O mecanismo de coordenação do tipo ajuste mútuo, apesar de ter sido indicado por um dos entrevistados, resultou como de menor impacto, enquanto a supervisão direta não foi indicada por nenhum deles como predominante.

Dessa forma, pode-se afirmar que o principal mecanismo de coordenação da configuração organizacional da UFC é a padronização dos processos de trabalho, característico da burocracia mecanizada. Entretanto, quando essa questão foi tratada considerando apenas a atividade-fim - ensino, pesquisa e extensão -, todos os entrevistados concordaram que há pouca ou nenhuma padronização dos processos. Portanto, sobre as atividades-fim da UFC, todos os entrevistados afirmaram que predomina o mecanismo de coordenação do tipo padronização de habilidades, visto que existe um treinamento específico para o desempenho do trabalho.

No caso da padronização dos processos de trabalho, o principal órgão apontado como responsável por essa atividade foi a Pró-Reitoria de Planejamento. Do ponto de vista da atividade-fim, de acordo com um dos entrevistados, a PRPL restringe-se a padronizar os processos ordinários, referentes a organização gerencial, isto é, padroniza os mecanismos que apenas balizam a sua execução, como, por exemplo, o uso de sistemas de informação 
gerencial (SIGAA - Sistema Integrado de Gestão de Atividades Acadêmicas); mas não interfere diretamente, nem planeja essa atividade. Outros mecanismos, citados nas entrevistas, como balizadores da atividade-fim, foram o plano departamental, o projeto pedagógico de curso e o programa da disciplina, instituídos no âmbito das unidades acadêmicas. De acordo com alguns dos entrevistados, também existem especificidades relativas à natureza de cada área do conhecimento que vão balizando a atuação dos professores na execução de suas atividades.

Sobre a padronização das habilidades, há dois parâmetros de design diretamente relacionados: o treinamento e a doutrinação. Para Mintzberg (2008, p. 53), quando o mecanismo de coordenação adotado é a padronização das habilidades, "os profissionais são treinados durante longos períodos de tempo, antes de assumirem suas posições.”. Essa característica ficou bastante evidente nas entrevistadas quando se tratou da forma como os profissionais da UFC são selecionados, principalmente aqueles do núcleo operacional, os professores; pois, tanto a legislação pertinente, quanto as normas da própria Universidade (Resolução $n^{0}$ 02/CEPE/2016) estabelecem um processo seletivo, por meio de concurso público, que exige desse profissional uma elevada formação acadêmica. Neste sentido, destaca-se a fala do entrevistado E1 (2016):

Os concursos para professores, na UFC, exigem um nível muito elevado de capacitação. Então, a própria lei e as regras da Universidade pedem que os concursos sejam realizados inicialmente a nível de doutorado. E aí, se não conseguir com nível de doutorado, tem que ter uma justificativa, que é avaliada pelo [...] CONSUNI... para que seja reaberto em nível de mestrado e ao mesmo tempo em nível de graduação, né? Então é bem difícil a gente ter pessoas que entrem para a atividade-fim que não tenham um alto nível de capacitação.

Um dos entrevistados, todavia, destacou o problema da falta de formação docente para o ensino superior no Brasil, visto que a maioria dos professores selecionados não são oriundos da licenciatura. Em virtude disso e outras possíveis lacunas, a UFC incentiva o desenvolvimento profissional de seus professores também após o ingresso, liberando-os para cursar programas de pós-graduação e para participar de congressos e seminários, incentivando a pesquisa e, ainda, oferecendo, ela mesma, cursos de capacitação pertinentes à atuação do professor. Sobre esse último caso, cabe destacar o Projeto CASa - Comunidade de Cooperação e Aprendizagem Significativa ${ }^{1}$, citado por todos os quatro entrevistados como

\footnotetext{
${ }^{1}$ Disponível em: <http://www2.virtual.ufc.br/casa/>. Acesso em: 28 de Julho de 2016.
} 


\section{A ESTRUTURA ORGANIZACIONAL DA UNIVERSIDADE FEDERAL DO CEARÁ (UFC): UM ESTUDO DE CASO À LUZ DA TEORIA DAS CINCO CONFIGURAÇÕES DE MINTZBERG \\ DOI: http://dx.doi.org/10.5007/1983-4535.2019v12n1p73}

uma ferramenta de treinamento e doutrinação destinada aos professores que estão cumprindo o período de estágio probatório.

De acordo com Mintzberg (2008, p. 51), “doutrinação é o processo pelo qual as normas organizacionais são adquiridas", através da doutrinação e do treinamento os padrões de comportamentos aceitos são internalizados pelos trabalhadores. Assim, outras ferramentas citadas pelos entrevistados como forma de doutrinação foram os seminários de ambientação, oferecidos para os servidores recém-ingressos e os seminários de lançamento de projetos de gestão para os quais é convidada toda a comunidade acadêmica. Duas características peculiares da UFC, nesse aspecto, também foram destacadas, de um lado a força da tradição, que promoveria uma adesão mais rápida de seus membros as normas organizacionais e, de outro, as práticas do dia-a-dia, responsáveis por ajustar seus membros ao ambiente organizacional.

O terceiro mecanismo de coordenação, nesta ordem, destacado como predominante foi a padronização dos resultados. Identificou-se três sistemas de planejamento e controle presentes na UFC: avaliação institucional, avaliação de desempenho docente e avaliação de desempenho dos servidores técnicos administrativos. Além disso, os entrevistados destacaram o papel da legislação e dos órgãos definidores de políticas para a educação sobre a padronização dos resultados, isto é, o MEC e, especificamente, o INEP (graduação) e a CAPES (pesquisa e pós-graduação); assim como das resoluções da própria Universidade ao estabelecer padrões de desempenho, caso da Resolução $n^{\circ}$ 22/CEPE/2014, que estabelece os critérios e procedimentos para a avaliação de desempenho e para a verificação do cumprimento dos requisitos necessários à progressão e à promoção por desempenho e/ou por titulação dos professores.

\subsection{PARTE-CHAVE DA ESTRUTURA ORGANIZACIONAL}

Mintzberg (2008) representa as cinco partes da configuração de uma organização como forças atuantes em sua estrutura, de tal modo que a cúpula estratégica representa força para centralizar; a tecnoestrutura força para padronizar; a assessoria de apoio força para colaborar; a linha intermediária força para fragmentar; e o núcleo operacional força para profissionalizar.

A cúpula estratégica da UFC, com base na análise da pesquisa documental e das entrevistas realizadas, é representada pela Reitoria, pela Vice-Reitoria, pelo Conselho Universitário, pelo Conselho de Ensino, Pesquisa e Extensão e pelo Conselho de Curadores. 


\section{A ESTRUTURA ORGANIZACIONAL DA UNIVERSIDADE FEDERAL DO CEARÁ (UFC): UM ESTUDO DE CASO À LUZ DA TEORIA DAS CINCO CONFIGURAÇÕES DE MINTZBERG DOI: http://dx.doi.org/10.5007/1983-4535.2019v12n1p73}

A linha intermediária, estaria representada pelos diretores de centro, faculdades, institutos e de campi. A assessoria de apoio seria composta pelas pró-reitorias, superintendências, órgãos suplementares, STI e Secretaria de Cultura Artística.

O organograma da administração acadêmica apresenta uma base composta por 16 unidades acadêmicas dentre faculdades, centros, institutos e os campi; essa base diversificada e alongada descreve o núcleo operacional, que é responsável pelas atividades-fim (ensino, pesquisa e extensão). Na análise de Mintzberg (2008), a parte-chave da organização é representada pela parte de onde emanam as decisões. Neste sentido, a forte autonomia do núcleo operacional da UFC, representado essencialmente por professores, foi bastante enfatizada por todos entrevistados; assim como a questão de a Universidade ter uma estrutura colegiada para a tomada de decisão, seja no plano departamental, configurado pelos conselhos de departamento e de centro, ou no plano estratégico pelo CONSUNI e CEPE. Todos esses órgãos colegiados têm forte representação dos professores, algo confirmado também na análise documental.

No que diz respeito à estrutura colegiada, destaca-se a seguinte fala: “[...] ela é colegiada. Aí é típico da organização profissional. O Reitor até que poderia dizer: 'olha, vai ser assim'. Mas para ele vai ser muito desgastante, então ele prefere deixar para o colegiado decidir porque aí vai para o CEPE e vai para o CONSUNI, que passa mais fácil”. (E3, 2016).

Todavia, também foi dada uma ênfase pelos entrevistados à tecnoestrutura, representada por: três pró-reitorias diretamente ligadas às atividades-fim (PROGRAD, PRPPG, PREX); legislações externas que regulamentam as atividades-fim; resoluções aprovadas nos CONSUNI e CEPE; órgãos de controle externo como Tribunal de Contas da União (TCU) e outros órgãos governamentais, como a Coordenação de Aperfeiçoamento de Pessoal de nível Superior (CAPES) e o Instituto Nacional de Estudos e Pesquisas Educacionais (INEP).

Observa-se então que há duas grandes forças presentes na UFC, uma força para padronizar os processos e outra para profissionalizar. Sobre a força para padronizar, percebese, na fala dos entrevistados, que ela está advindo de um controle externo cada vez mais atuante:

[...] a avaliação externa ela está cada vez mais contundente e ela serve de referência para aquilo que se espera de nós. Na pós-graduação, a avaliação da CAPES que dá nota aos cursos, se um curso obtiver duas notas baixas seguidas, ele é descredenciado. Na graduação é o INEP, que avalia os cursos de graduação em triênios, o que pode descredenciar cursos ou fazê-los baixar em diligências. Nós temos, hoje, pelos órgãos que avaliam, um conjunto de 


\section{A ESTRUTURA ORGANIZACIONAL DA UNIVERSIDADE FEDERAL DO CEARÁ (UFC): UM ESTUDO DE CASO À LUZ DA TEORIA DAS CINCO CONFIGURAÇÕES DE MINTZBERG \\ DOI: http://dx.doi.org/10.5007/1983-4535.2019v12n1p73}

itens de avaliação, que referenciam o trabalho de quem está nessa base acadêmica $[\ldots](\mathrm{E} 4,2016)$.

Essa força para padronização, demandada principalmente pelos órgãos de controle externo da administração pública, acaba sobrepujando outras partes da UFC, em especial a assessoria de apoio e a linha intermediária, pois exigem, inclusive, uma padronização das atividades do núcleo operacional. Assim, apesar da força para profissionalização ser predominante, até pelo fato de ser uma instituição de ensino, sendo configurada tipicamente como burocracia profissional, percebe-se a tecnocracia agindo de forma bastante atuante na Universidade, sendo uma característica mais típica das burocracias mecanizadas.

\subsection{TIPO DE DESCENTRALIZAÇÃO PREVALECENTE}

O processo de tomada de decisão na UFC é essencialmente realizado através de sua estrutura colegiada, tanto na administração superior quanto na administração acadêmica. Assim, de acordo com o Art. $3^{\circ}$ do seu Regimento Geral (UFC, 2015c), são os seguintes os colegiados deliberativos da Universidade: os departamentos, as coordenações de curso de graduação e pós-graduação, os Conselhos de Centro e os Conselhos Departamentais, o Conselho Universitário, o Conselho de Ensino, Pesquisa e Extensão e o Conselho de Curadores. O funcionamento desses órgãos também é definido em Regimento Geral (UFC, 2015c), conforme o exposto no capítulo II. No Estatuto (UFC, 2015a), por sua vez, está disposto como se dá a composição dos órgãos colegiados, assim como quais são as competências atribuídas a cada um deles. Além dessa estrutura colegiada, o Estatuto também definirá as competências dos órgãos executivos, assim definidos no Regimento Geral (UFC, 2015c): Reitoria, Centros e Faculdades. Ainda, conforme o Art. 115 do Estatuto (UFC, 2015a, p. 40): “Os docentes ocuparão 70\% (setenta por cento) dos assentos dos órgãos colegiados dos quais participem segmentos da comunidade institucional, local e regional, inclusive nos que tratarem da elaboração e modificações estatutárias e regimentais.”.

Dessa forma, pode-se afirmar que há um regime representativo, principalmente do núcleo operacional da organização, que realiza a maior parte das decisões da UFC. Assim, como já citado no subtópico anterior, na fala do entrevistado E3, a tomada de decisão na UFC é colegiada, típica de uma organização profissional. Embora essas decisões sejam balizadas pela legislação pertinente e pelos órgãos de controle da administração pública, no que diz respeito a sua configuração organizacional, a UFC apresenta uma estrutura altamente 


\section{A ESTRUTURA ORGANIZACIONAL DA UNIVERSIDADE FEDERAL DO CEARÁ (UFC): UM ESTUDO DE CASO À LUZ DA TEORIA DAS CINCO CONFIGURAÇÕES DE MINTZBERG \\ DOI: http://dx.doi.org/10.5007/1983-4535.2019v12n1p73}

descentralizada vertical e horizontalmente. Segundo Mintzberg (2008, p. 220), isso é próprio da burocracia profissional porque "o poder profissional deriva não apenas do fato de seu trabalho ser bastante complexo para ser supervisionado por gerentes ou padronizado por analistas, mas também de seus serviços serem, tipicamente, de grande exigência.”. É por isso também que, na burocracia profissional o trabalho é verticalmente ampliado, isto é, a organização "contrata profissionais especializados, devidamente treinados e doutrinados, para o núcleo operacional e, depois, concede-lhes considerável controle sobre seu próprio trabalho.” (MINTZBERG, 2008, p. 213).

\subsection{DIFICULDADES E FACILITADORES PROPORCIONADOS PELA CONFIGURAÇÃO ORGANIZACIONAL DA UFC}

De acordo com análise dos dados coletados por meio das entrevistas, foram indicadas como dificuldades proporcionadas pela configuração organizacional da UFC: a complexidade estrutural, o conservadorismo, a dimensão política, a burocratização, a falta de autonomia e flexibilidade e o controle externo.

Assim, foi apontado que a complexidade estrutural dificulta a realização de tarefas típicas da administração, como planejamento e coordenação e também impede a existência de um sistema eficiente de governança. O conservadorismo prejudicaria a renovação das práticas administrativas e da organização curricular, que dá pouco protagonismo ao estudante. A dimensão política se manifestaria em dois momentos, primeiro no espaço de disputas presentes nas reuniões dos colegiados que, por vezes, poderiam ser influenciadas por questões de poder e, segundo, no desempenho dos ocupantes de cargos eletivos dentro da instituição, cuja atuação poderia estar mais baseada na expectativa de recondução dos seus mandatos do que na competência. A burocratização, por sua vez, teria impacto negativo principalmente na morosidade do processo de tomada de decisão, tanto das decisões colegiadas quanto daquelas tomadas por comandos hierárquicos superiores.

A falta de autonomia estaria relacionada a não correspondência entre a autonomia universitária constitucionalmente garantida e a realidade praticada, seja autonomia financeira e patrimonial, didático-científica ou administrativa, como no caso da contratação de novos servidores. Já a falta de flexibilidade estaria relacionada, principalmente, à submissão da Universidade a legislações federais cujas determinações desconsideram as especificidades dessas instituições de ensino; um caso crítico bastante citado é a lei de licitações e contratos públicos. Por fim, o controle externo foi apontado como uma dificuldade nos casos em que 
extrapola questões relativas ao uso de dinheiro público e passam a interferir na autonomia universitária: “[...] as interferências externas que a gente sofre não são razoáveis (CGU)”. (E2, 2016). Além das dificuldades apresentadas, também foram mencionados como problemas, a comunicação dentro da instituição e os sistemas de avaliação de desempenho, no que diz respeito à qualidade dos resultados e às falhas dos sistemas de premiação e punição.

Quanto aos facilitadores, os dados indicaram a pesquisa, a participação e a burocratização. A pesquisa foi apontada como a atividade-fim mais beneficiada pela configuração organizacional da UFC, graças ao empreendedorismo fomentado pelas políticas públicas, em especial da CAPES, apesar das ressalvas feitas ao dito "produtivismo acadêmico". A participação está inserida na forma como são tomadas a maioria das decisões da UFC, por meio de seus colegiados, o que garante representatividade e impessoalidade às decisões: “[...] a vantagem do modelo colegiado é que as decisões são muito discutidas, os problemas são muito antevistos, as decisões quando são tomadas são muitos amadurecidas”. (E2, 2016).

A burocratização, embora também tenha sido citada como uma dificuldade, foi indicada por um dos entrevistados como um facilitador, visto que a Universidade ainda carece de um nível de padronização que oriente melhor as suas práticas. Assim, destaca-se a seguinte fala:

[...] hoje eu acho que são facilitadores, porque eu acho que a gente não atingiu um meio-termo ainda, eu acho que falta mais padronização do que sobra, padronizar mais não significa chegar a $100 \%$ de padronização, é atingir um nível de padronização que oriente melhor (E4, 2016).

\section{CONSIDERAÇÕES FINAIS}

Nessa última sessão, são apresentadas algumas considerações finais sobre o presente artigo, focalizando de que forma foram contemplados cada um dos objetivos específicos do trabalho. Além disso, são apresentadas as principais limitações e contribuições do trabalho. Por fim, algumas sugestões para futuras pesquisas são apresentadas.

De acordo com o primeiro objetivo específico, que foi identificar o principal mecanismo de coordenação da UFC, constatou-se a predominância de mais de um mecanismo, sendo o primeiro a padronização dos processos de trabalho, seguido pela padronização das habilidades. Pressupõe-se que essa força mais preocupada com a padronização dos processos decorre do fato de que todos os entrevistados pertencem, 


\section{A ESTRUTURA ORGANIZACIONAL DA UNIVERSIDADE FEDERAL DO CEARÁ (UFC): UM ESTUDO DE CASO À LUZ DA TEORIA DAS CINCO CONFIGURAÇÕES DE MINTZBERG DOI: http://dx.doi.org/10.5007/1983-4535.2019v12n1p73}

atualmente, aos quadros de gestão da administração superior da Universidade, ainda que três deles também sejam docentes pertencentes aos quadros da administração acadêmica.

Quanto ao segundo objetivo específico, que buscou identificar a parte-chave da estrutura organizacional da UFC, conclui-se, a partir da pesquisa documental e da análise das entrevistas, que o núcleo operacional, composta pelo quadro de professores, é a parte-chave da organização. Contudo, ficou constatado também uma crescente influência da tecnoestrutura com as atuações cada vez mais fortes dos órgãos de controle externo. Além disso, a assessoria de apoio, que deve, na visão de Mintzberg, dar sustentações colaborativas para a atividade-fim, acaba sendo atraído por essas forças padronização cada vez mais presentes na Universidade em estudo.

Tendo em vista o terceiro objetivo específico, que foi identificar o tipo de descentralização prevalecente na instituição, ficou constatado que prevalece na UFC a descentralização vertical através da estrutura colegiada desenvolvida nos conselhos, além da descentralização horizontal que dá forte controle e autonomia ao trabalho realizado pelos operadores das atividades-fim, representados pelos professores. Decorre, portanto, que a UFC apresenta um tipo de descentralização horizontal e vertical. Assim, tomando como base a análise dos três primeiros objetivos, conclui-se que a configuração organizacional da UFC, atualmente, é híbrida entre a Burocracia Profissional e a Burocracia Mecanizada

De acordo com o quarto objetivo específico, que buscou identificar as dificuldades ocasionadas pela configuração organizacional da UFC, constatou-se que essa configuração híbrida tem proporcionado algumas barreiras ao cumprimento dos objetivos institucionais: a demora na tomada de decisões, o forte conservadorismo em relação às mudanças e inovações dos processos e a falta de autonomia e flexibilidade provocada pelo forte aparato tecnocrático presente. O que acaba confirmando os estudos anteriores apresentados nesse artigo.

Quanto ao último objetivo específico, que foi identificar os facilitadores proporcionados pela configuração organizacional da UFC, foram apresentados poucos facilitadores dentro da atual configuração híbrida. A própria burocracia, ao mesmo tempo que foi apresentada como barreira, foi enfatizada como necessária para melhorar as práticas voltadas ao ensino. A preponderância dada na fala dos entrevistadores às dificuldades em detrimento dos facilitadores pode estar relacionada ao fato de todos eles, atualmente, estão mais diretamente ligados à gestão da Universidade do que, propriamente, às atividades-fim. Assim, uma primeira sugestão para futuros trabalhos é incluir nas entrevistas cargos 
relacionados à linha intermediária e ao núcleo operacional da Universidade, ampliando a diversidade e pluralidade de pensamentos dos dados.

Assim, dentre as limitações desse trabalho, destaca-se a necessidade de ampliar o número de entrevistas, principalmente com gestores da administração acadêmica da UFC, como chefes de departamento e diretores de centro e faculdades. Já como principais contribuições, acredita-se que os resultados encontrados servem de diagnóstico à gestão da Universidade, podendo ser utilizados como ponto de partida na busca de melhores práticas de gestão em seus diversos campos de atuação. Além disso, o estudo realizado também pode ser encarado como modelo e referência para estudos futuros, seja na própria UFC ou em outras IFES.

Por fim, como sugestão adicional deste trabalho, propõe-se que sejam realizados estudos futuros que explorem a mesma percepção utilizada, porém com maior número e diversidade de universidades, para que se possa analisar a configuração predominante das universidades brasileiras e, quem sabe, internacionais, e como essa configuração tem contribuído para o cumprimento de seus objetivos institucionais, visando assim à melhoria das práticas de gestão nas universidades federais brasileiras.

\section{REFERÊNCIAS}

COLLIS, Jill; HUSSEY, Roger. Pesquisa em administração: um guia prático para alunos de graduação e pós-graduação. 2 ed. Porto Alegre: Bookman, 2005.

CUNHA; J. A. C. da; YOKOMIZO, C. A.; BONACIM, C. A. G. Miopias de uma lente de aumento: as limitações da análise de documentos no estudo das organizações. In: ENCONTRO DA ASSOCIAÇÃO NACIONAL DE PÓS-GRADUAÇÃO E PESQUISA EM ADMINISTRAÇÃO, 34., 2010, Rio de Janeiro. Anais... Rio de Janeiro: ANPAD, 2010.

FACHIN, R. C. Estratégias e gestão de universidades. In: KLERING, L. R. Temas contemporâneos sobre gestão universitária. Florianópolis: BOOKESS, 2013. p. 19-24.

FREITAS, I. M. A. C. Configurações estratégicas em universidades federais brasileiras. Florianópolis, 2002. 278f. Tese (Doutorado em Engenharia de Produção). Programa de Pósgraduação em Engenharia de Produção. UFSC, 2002.

LOSEKANN, V. L.; SALDANHA, J. M. L. A universidade federal inserida num contexto globalizado de reformas e inovações do estado contemporâneo. Revista Sociais e Humanas, Santa Maria, v. 20, p.83-102, set. 2007. Edição especial. 
MARKS, S.R. A configuração organizacional da universidade de Ijuí e suas repercussões. Porto Alegre: UFRGS, 1993. 278 f. Dissertação de Mestrado. Programa de Pós-Graduação da Universidade Federal do Rio Grande do Sul. UFRGS, Porto Alegre. 1993.

MINTZBERG, H. Criando organizações eficazes: estruturas em cinco configurações. 2. ed. São Paulo: Atlas, 2008.

The structuring of organizations. Englewwod Cliffs. Prentice-Hall, 1979.

PEIXOTO, A. L. A.; SOUZA, J. A. J. Longe dos olhos, longe do coração: desafios de gestão de uma universidade pública a partir da percepção dos seus gestores. Revista de Gestão Universitária da América Latina, Florianópolis, vol. 8, n. 03, p. 240-260, 2015.

PINHEIRO, H. D. Redesenho das configurações estruturais na gestão universitária: ações derivadas da inovação e flexibilidade na legislação pós-LDB 1996. Natal: UFRN, 2011. 359 f. Tese de Doutorado. Programa de Pós-Graduação em Administração da Universidade Federal do Rio Grande do Norte. UFRN, Natal, 2011.

SAMPIERI, R. H.; COLLADO, C. F.; LUCIO, P. B. Metodologia de pesquisa. 5. ed. São Paulo: McGraw-Hill, 2013.

SILVA, A. H.; FOSSÁ, M. I. T. Análise de conteúdo: exemplo de aplicação da técnica para análise de dados qualitativos. In: ENCONTRO DE ENSINO E PESQUISA EM ADMINISTRAÇÃO E CONTABILIDADE, 4., 2013, Brasília. Anais... Brasília: ANEPEQ, 2013.

SOUZA, S.; PRADO, V. J. Imagens da escola como organização: uma análise comparativa entre o modelo burocrático e a anarquia organizada através de metáforas. In: ENCONTRO DA ASSOCIAÇÃO NACIONAL DE PÓS-GRADUAÇÃO E PESQUISA EM ADMINISTRAÇÃO, 33., 2009, São Paulo. Anais... São Paulo: ANPAD, 2009.

TRIGUEIRO-FERNANDES, L. Estrutura e desempenho organizacional: uma análise na Universidade Federal do Rio Grande do Norte. Natal, UFRN, 2014. 130 f. Dissertação de Mestrado. Programa de Pós-Graduação em Administração da Universidade Federal do Rio Grande do Norte. UFRN, Natal, 2014.

UNIVERSIDADE FEDERAL DO CEARÁ. Estatuto da UFC. Fortaleza, 2015a. Disponível em: <http://ufc.br/images/_files/a_universidade/estatuto_ufc/estatuto_ufc.pdf $>$. Acesso em: 30 junho 2016.

UNIVERSIDADE FEDERAL DO CEARÁ. Estrutura organizacional. Fortaleza, 2015b. Disponível em: < http://www.ufc.br/acessoainformacao/institucional/13-estruturaorganizacional>. Acesso em: 30 junho 2016.

UNIVERSIDADE FEDERAL DO CEARÁ. Regimento geral da UFC. Fortaleza, 2015c. Disponível em: $<$ http://ufc.br/images/_files/a_universidade/regimento_geral_ufc/ regimento_geral_ufc.pdf>. Acesso em: 30 junho 2016. 
VIEIRA, Euripedes Falcão; VIEIRA, Marcelo M. Falcão. Estrutura organizacional e gestão do desempenho nas universidades federais brasileiras. RAP - Revista de Administração Pública. v. 37. n.4, jul./ago. p. 899-920, 2003.

YIN, Robert K. Estudo de caso. 2. ed., Porto Alegre: Bookman, 2010. 